\title{
Classical discrimination conditioning of heart rate and bar-press suppression in the rat '
}

JAN PARRISH $^{2}$

UNIVERSITY OF MIAMI

Eight rats, previously trained on a variable interval (VI-30 sec) schedule for food reinforcement, received two days of adaptation to tones and five days of classical discrimination conditioning in which one of two tones was paired with shock. The major findings were (a) responses to the CS+ included barpress ( $B-P$ ) suppression and a decrease in heart rate (HR); (b) responses to the CS-included B-P facilitation and an increase in HR; (c) changes in HR conditioned more slowly than changes in B-P; and (d) the HR response topography indicated that most $H R$ responding occurred in the latter half of the CS-US interval.

The purpose of the present experiment was to concomitantly assess classical discrimination conditioning of HR and B-P suppression in rats and to determine the topography of the HR response. Previously, Stebbins \& Smith (1964) demonstrated that HR changes occur during B-P suppression, and DeToledo \& Black (1966) found that $\mathrm{HR}$ conditioned more slowly than B-P suppression. In our own laboratory Meredith \& Schneiderman (1967), Swadlow \& Schneiderman (1967), VanDercar \& Schneiderman (1967), and Yehle (1966) have also documented divergences in performance between HR and skeletal responses. These differences in rabbit response systems occurred in rate of $C R$ acquisition, discrimination capability, reactivity to drugs, shape of the interstimulus interval function, and performance under delay versus trace conditioning procedures.

Method

Eight male Long-Evans hooded rats, approximately 90 days old, were maintained at $85 \%$ of the weight of littermate control Ss who were not food deprived. Using $45 \mathrm{mg}$ rat pellets as reinforcers the experimental Ss were trained daily for three weeks until fairly stable VI-30 sec behavior was obtained. Then, superimposed upon the VI-30 sec schedule the Ss received two days of adaptation to $1.5 \mathrm{~min}$ duration 1800 and $510 \mathrm{cps}$ tones at $56 \mathrm{~dB}$ SPL followed by five acquisition days of classical discrimination conditioning.

Each adaptation and acquisition session was divided into $331.5 \mathrm{~min}$ intervals. During acquisition sessions the Ss received six intervals of one frequency tone unpaired with shock. These were interspersed with six intervals in which the other frequency tone was followed by a .5 sec duration, $1.3 \mathrm{~mA}$ shock delivered through a grid floor. The tone intervals were never presented immediately adjacent to one another in time, but were always separated by intervals in which no stimuli were presented. During each session a record was kept for each $S$ of number of bar presses during each $1.5 \mathrm{~min}$ interval. A concomitant record was made of $H R$. The topography of the HR response was obtained by counting the number of beats during the 60 sec preceding tone onset, dividing by four and comparing this with the number of beats occurring during six successive $15 \mathrm{sec}$ intervals after CS onset. For statistical analyses HR scores were determined by taking the number of beats occurring during the $60 \mathrm{sec}$ preceding CS onset, multiplying by 1.5 and comparing this figure with the number of beats occurring during the $90 \mathrm{sec}$ CS-US interval.

During experimental sessions each $S$ was run in a 12 in. $x 10$ in. $x 12$ in. operant conditioning box having a shock grid floor and aluminum cover. The box was equipped with a Gerbrands rat lever and the outlet tube of a Davis CB-106 feeder. Measures of HR were obtained by means of two stainless steel safety pins inserted into the skin of the S's right shoulder and left haunch and connected to a Model 111 A Grass EEG machine. Bar press recordings were concomitantly obtained from a Harvard cumulative recorder and a bank of 10 sedeco counters.

Results

The topography of HR responses to the reinforced (CS+) and nonreinforced (CS-) tones during the second adaptation and all acquisition sessions are shown in Fig. 1. It can be seen that there was little responding to either tone during the second adaptation session,

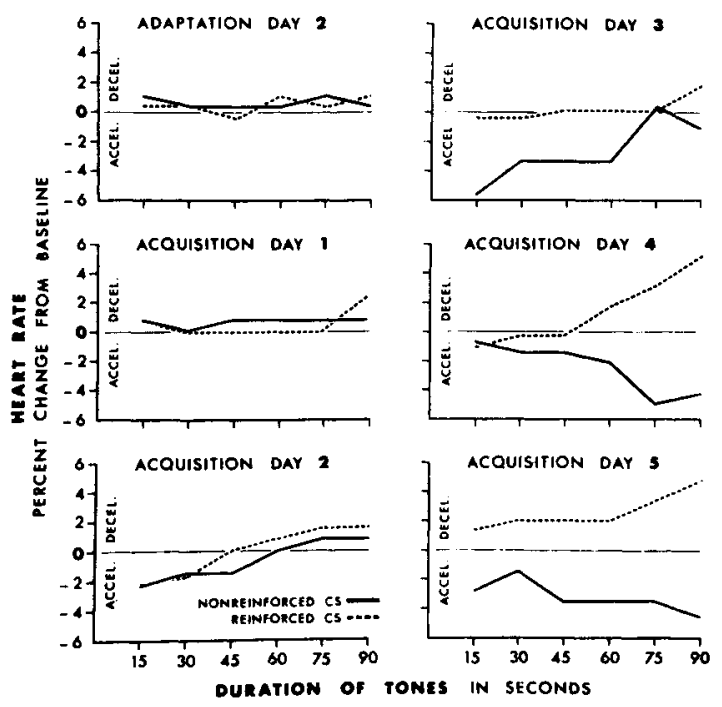

Fig. 1. Mean response topography of heart rate to the reinforced (CS+) and nonreinforced (CS-) tones. 


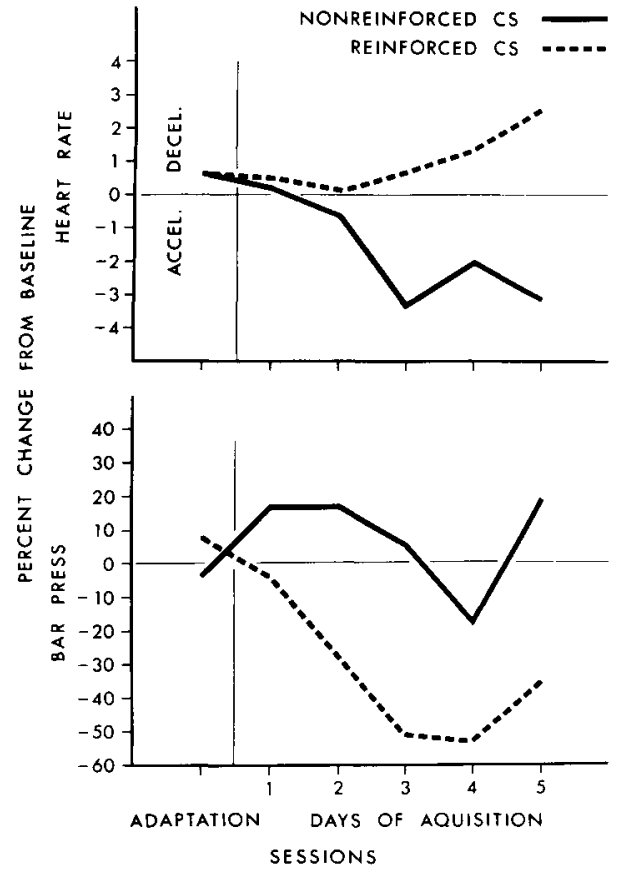

Fig. 2. Percent change from baseline of heart rate and bar-press responses to each CS during adaptation and acquisition.

and little evidence of differential responding until Day 3 of acquisition. In the third acquisition session there was a marked HR acceleration to the CS-, but little response to the CS+ occurred during the CSUS interval. In contrast, during the fourth and fifth acquisition sessions there was a marked decrease in $\mathrm{HR}$ to the $\mathrm{CS}+$ as well as a pronounced increase to the CS-.

In the course of training the largest portion of the response to the CS+ began to occur in the second half of the CS-US interval, increasing progressively until US onset. A t-test of paired comparisons conducted upon the difference in HR responding to the CS+ between the first and second half of the CS-US interval cumulated over all acquisition trials was reliable $(p<.05)$.

The percentage changes from baseline of $\mathrm{HR}$ and B-P responses during adaptation and acquisition are depicted in Fig. 2. The HR frame indicates that: (a) little differential HR conditioning occurred during the first two acquisition sessions; (b) marked differential HR conditioning occurred during the last three sessions; and (c) the magnitude of the responses to the CS+ increased from the third to fifth sessions. The B-P frame indicates that: (a) differential rates of B-P occurred during each acquisition session; (b) in four of the five sessions the response to the CS+ was a small increase in B-P rate whereas the response to the CS- was a relatively larger suppression of B-P.

A t-test of paired comparisons conducted upon the difference in HR percentage change from baseline to the CSt and the CS- cumulated over the first two acquisition sessions was not significant, but a similar analysis conducted over the last three acquisition sessions was reliable $(p<.05)$. In contrast to the HR findings, t-tests of paired comparisons conducted upon the differences in B-P to the CS+ and CS- revealed reliable differences $(p<.05)$ during each acquisition session including Day 1.

\section{Discussion}

The present finding that the HR response to the CS+ in rats was a decrease in rate confirms the previous observations of DeToledo \& Black (1966), and agrees with similar findings in rabbits (e.g., Schneiderman, Smith, Smith, \& Gormezano, 1966; Yehle, Dauth, \& Schneiderman, 1967). Our observation that changes in HR condition more slowly than changes in B-P are also in agreement with those of DeToledo and Black.

The finding in the present study that HR decreases to the CS+ were accompanied by B-P suppression, whereas HR increases to the CS- were accompanied by a slight facilitation is consistent with Obrist's(1965) suggestion that HR deceleration is related to an inhibition and HR acceleration to an augmentation of voluntary motor activity. This suggests that the Ss may not only have learned a single response (i.e., to respond to a tone paired with shock), but may have learned two separate classes of responses associated with different reinforcement contingencies. In particular, the augmentation of bar pressing observed in the presence of the CS- suggests that this stimulus may have signaled a "safe-period" in which neither the shock nor the discriminative stimulus signaling shock was imminent.

References

DeTOLEDO, L., \& BLACK, A. H. Heart rate: Changes during conditioned suppression in rats. Science, 1966, 152, 14041406.

MEREDITH, A., \& SCHNEIDERMAN, N. Heart rate and nictitating membrane classical discrimination conditioning in rabbits under delay versus trace procedures. Psychon. Sci, 1967, in press.

OBRIST, P. A. Heart rate during conditioning in dogs: Relationship to respiration and gross bodily movements. Proc. 73rd Annu. Conv. Amer. Psychol. Assoc, 1965, 165-166.

SCHNEIDERMAN, N., SMITH, M. C., SMITH, A. C., \& GORMEZANO, I. Heart rate classical conditioning in rabbits. Psychon. Sci., 1966, 6, 241-242.

STEBBINS, W. C., \& SMITH, O. K., Jr. Cariovascular concomitants of the conditioned emotional response in the monkey. Science, 1964, $144,881-885$.

SWADLOW, H., \& SCHNEIDERMAN, N. Magnesium pemoline: Facilitation and debilitation of heart rate classical discrimination conditioning in rabbits. Psychon. Sci, 8, 481-482.

VanDERCAR, D. H., \& SCHNEIDERMAN, N. Interstimulus interval functions in different response systems during classical discrimination conditioning of rabbits. Psychon. Sci, 1967, in press.

YEHLE, A. L. Divergent characteristics of response systems in rabbits as a function of a three tone classical discrimination situation. Unpublished doctoral dissertation. University of Miami, 1966.

YEHLE, A. L., DAUTH, G. W., \& SCHNEIDERMAN, N. Correlates of heart rate classical corditioning in curarized rabbits. J. comp. physiol. Psychol., 1967, 64, 98-104.

Notes

1. This report is based upon a doctoral dissertation submitted to the University of Miami in 1966. The work was supported by NSF grant GB-5307 to N. Schneiderman, my thesis adviser, to whom I am indebted for guidance throughout the experiment.

2. Now at Henderson Clinic, Fort Lauderdale, Florida. 